\title{
APLIKASI MONITORING CAPAIAN KOMPETENSI PESERTA DIDIK DI SMA KOLOMBO YOGYAKARTA
}

\author{
Andika Bayu Saputra, Ari Cahyono \\ Jurusan S-1 Teknik Informatika, Fakultas Teknik dan Teknologi Informasi \\ Universitas Jenderal Achmad Yani Yogyakarta \\ Jl. Siliwangi KM 0,7 Ringroad Barat Banyuraden Gamping Sleman \\ dika.putra21@gmail.com, arcaism@gmail.com
}

\begin{abstract}
Colombo Colombo High School is an educational institution in charge of handling activities related to education. As an educational institution at present the 2013 curriculum report report data management still uses Microsoft Excel applications with the step of the subject teacher submitting the file value to the homeroom teacher and the homeroom teacher will process the value data and submit it to the curriculum section for printing. Of course this requires a long time and is not effective. Another problem that arises is that the current process is perceived to be less optimal and efficient, the guardian of the student must go to the school every semester which requires a lot of time for the guardians of students who cannot attend the division of the Colombo Colombo High School students' achievement report and the report can only be seen at a certain time. This research was designed and built using the CodeIgniter framework and uses a MySQL database as well as the System Development Life Cycle (SDLC) method of the waterfall model which can help the school, namely teachers, homerooms and curriculum parts in terms of report card management and for learners. Based on the results of the research that has been done, it is concluded that the application of monitoring the achievement of students' competencies provides convenience for the school and parents to monitor the development of students. Because this application is web-based teachers and school principals at any time can see the results of the development process of students without having to wait for the distribution of report cards to take place, parents can ask about the development of the value of their children at any time and the search for student assessment data will be faster.
\end{abstract}

Keyword: Achievement report application, SDLC, Waterfall.

\section{Latar Belakang Masalah}

SMA Kolombo Yogyakarta merupakan lembaga pendidikan yang bertugas menangani kegiatan-kegiatan yang berkaitan dengan pendidikan. Sebagai instansi pendidikan, pada saat ini pengelolaan data nilai rapor kurikulum 2013 masih menggunakan aplikasi Microsoft Excel dengan tahapan guru mata pelajaran menyerahkan nilai dalam bentuk file kepada wali kelas kemudian wali kelas akan memproses data nilai tersebut dan diserahkan ke bagian kurikulum untuk dicetak. Tentu saja hal ini memerlukan waktu yang cukup lama dan tidak efektif. Disamping itu pemanfaatan teknologi internet yang masih kurang, salah satunya dalam hal pembagian atau pengaksesan laporan pencapaian peserta didik yang dilakukan secara manual, setiap wali kelas untuk membagikan laporan pencapaian kompetensi peserta didik dan wali peserta didik harus datang ke sekolah tersebut untuk memperoleh hasil belajar anaknya selama 1 semester.

Permasalahan yang muncul adalah pada proses yang berjalan saat ini dirasa kurang optimal dan efisien, wali peserta didik harus mendatangi sekolah tersebut setiap semesternya yang sangat membutuhkan banyak waktu bagi wali peserta didik yang tidak dapat menghadiri pembagian laporan pencapaian peserta didik SMA Kolombo Yogyakarta dan laporan tersebut hanya bisa dilihat pada waktu tertentu. Wali peserta didik masih mengalami kesulitan dalam memonitoring perkembangan laporan capaian kompetensi yang telah diperoleh peserta didik 
selama 1 semester. Ketika mencari data atau informasi tentang perkembangan laporan pencapaian akan membutuhkan waktu yang lama apabila data tersebut diperlukan. Data nilai peserta didik hanya bisa diketahui nilai hasil akhirnya setelah akhir semester.

Pada penelitian ini dirancang dan dibangun sebuah aplikasi monitoring capaian kompetensi peserta didik berbasis web dengan menggunakan framework CodeIgniter dan menggunakan database MySQL serta metode System Development Life Cycle (SDLC) model waterfall yang dapat membantu pihak sekolah yaitu guru, wali kelas dan bagian kurikulum dalam mengelola nilai rapor serta wali peserta didik dalam memonitoring perkembangan peserta didik.

\section{Metodologi Penelitian}

Penelitian ini merupakan penelitian dengan menggunakan metode SDLC (System Development Life Cycle) dengan model air terjun (waterfall). Model ini menyediakan pendekatan alur hidup perangkat lunak secara skuensial atau terurut dimulai dari identifikasi dan analisis kebutuhan, desain sistem, pengkodean, implementasi sistem/pengujian dan tahap pemeliharaan (maintenance). Secara garis besar metode waterfall terdiri dari beberapa tahapan diantaranya (Presshman, 2001) :

1. Tahap identifikasi dan analisis kebutuhan

Dalam tahap ini akan dilakukan proses pengumpulan data secara intensif untuk mespsesifikasikan kebutuhan perangkat lunak agar dapat dipahami oleh user.

2. Tahap desain sistem

Dalam tahap ini akan dilakukan perancangan interface dan model sistem dengan menggunakan flowchart dan UML.

3. Tahap Pengkodean

Dalam tahap ini desain harus ditranslasikan kedalam program perngkat lunak. Hasil dari tahap ini adalah program komputer sesuai dengan desain yang telah dibuat pada tahap desain sistem.

4. Tahap implementasi sistem

Dalam tahap ini akan dilakukan proses implementasi dari desain perancangan pada tahap kedua kedalam bahasa pemrograman.

5. Tahap pengujian sistem

Dalam tahap ini akan dilakukan pengujian dari segi lojik dan fungsional untuk memastikan bahwa semua bagian sudah diuji. Hal ini dilakukan untuk meminimalisir kesalahan (eror) dan memastikan keluaran yang dihasilkan sesuai dengan yang diinginkan. Pengujian sistem ini dengan metode blackbox testing terhadap fitur-fitur program yang dikembangkan. Pengujian ini dilakukan oleh pihak seolah untuk mengetahui apakah aplikasi yang telah dibangun sudah sesuai dengan apa yang diharapkan atau masih ada kekurangan dan tambahan.

6. Perawatan (maintenance) Perawatan termasuk perbaikan kesalahan yang tidak ditemukan pada tahapan sebelumnya. Kegiatan yang dilakukan dalam pemeliharaan sistem yaitu dengan melakukan pengecekan pada sistem berkaitan dengan fungsi yang ditentukan sebeumnya sudah berjalan sebagaiamana mestinya.

\subsection{Prinsip Kerja Sistem}

Sistem yang ada saat ini sudah berbasis komputer, tetapi masih belum menerapkan sistem basis data yang terstruktur. Aplikasi yang digunakan terbatas hanya pada aplikasi Microsoft Office Excel dan Word yang disediakan oleh pihak sekolah. Mekanisme yang berjalan pada sistem saat ini dapat dijelaskan pada gambar 1. 


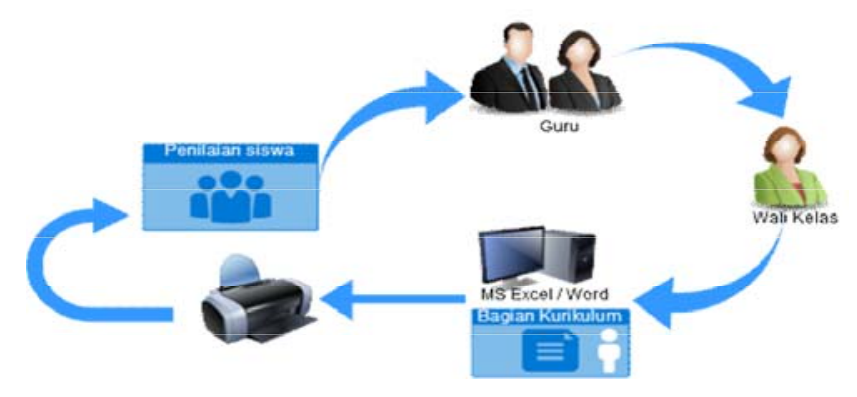

Gambar 1. Alur penilaian siswa

Dari gambar 1 dapat dijelaskan bahwa alur penilaian siswa pada sma kolombo masih dilakukan masih menggunakan aplikasi Microsoft Excel dengan tahapan guru mata pelajaran menyerahkan nilai dalam bentuk file kepada wali kelas kemudian wali kelas akan memproses data nilai tersebut dan diserahkan ke bagian kurikulum untuk dicetak.

Secara umum, alur data pada aplikasi yang dikembangkan akan tampak seperti pada gambar 2. Proses pengelolaan data yang dilakukan oleh aplikasi laporan capaian kompetensi siswa akan menghasilkan laporan akhir pada penilaian yang proses datanya dimasukan secara bertahap sehingga dapat diakses oleh pengguna yang terkait.

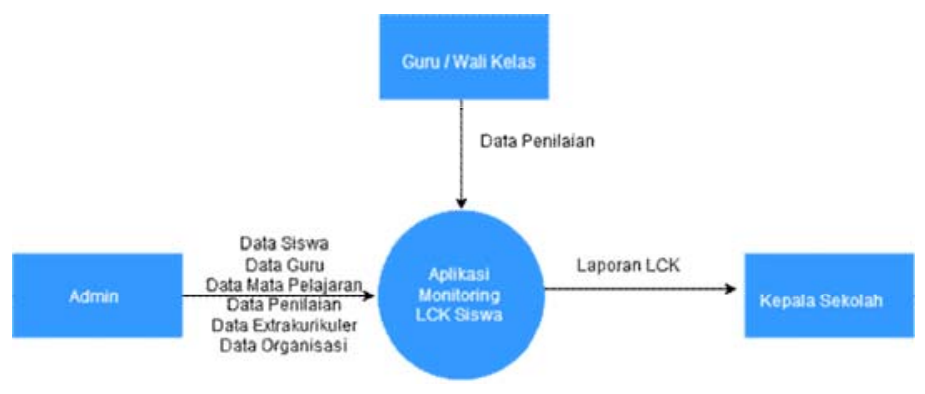

Gambar 2. DFD Level 0

Untuk memperjelas proses DFD level 0, maka proses yang lebih rinci dapat dilihat seperti pada gambar 3. Data siswa, guru / wali kelas, mata pelajaran, kelas, exstrakurikuler, organisasi proses entri data dilakukan oleh admin / operator. Data - data tersebut nantinya akan digunakan sebagai data pendukung untuk penilian siswa. Data yang telah di entrikan akan menjadi master data yang digunakan untuk melengkapi data penilaian. Hasil entri data akan diproses menjadi laporan penilaian yang akan di olah oleh aplikasi dan dapat di lihat oleh kepala sekolah untuk memonitoring. 


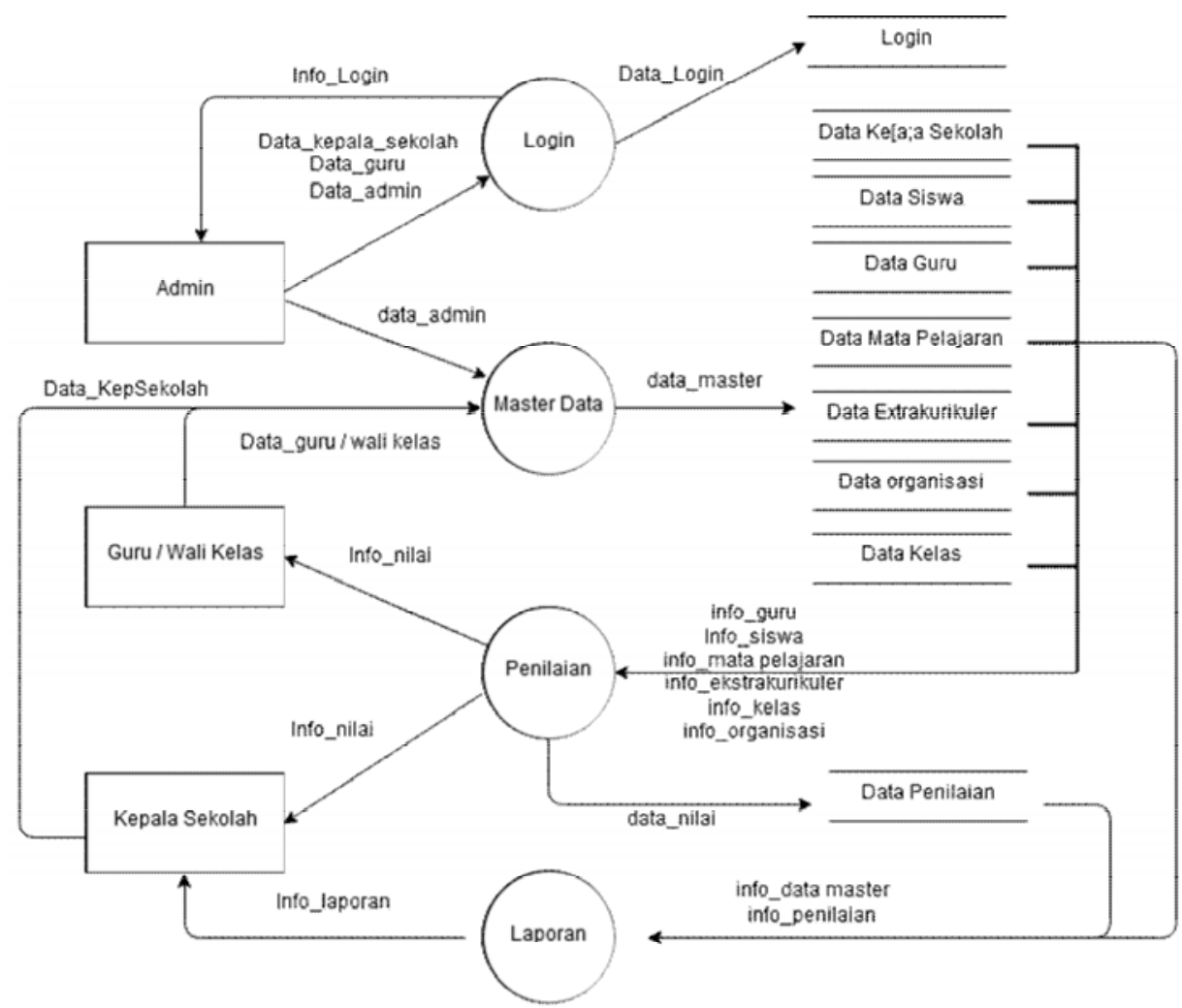

Gambar 3. DFD Level 1 Aplikasi LCK

\subsection{Sistem yang dikembangkan.}

Sistem yang dikembangkan yaitu perangkat lunak berbasis web yang berfungsi sebagai monitoring laporan capaian kompetensi siswa. Data yang diolah dan dihasilkan oleh aplikasi ini akan menjadi laporan untuk memonitoring perkembangan siswa didik. Pencarian dan penyimpanan data akan lebih tertata rapi serta bisa diakses oleh guru sewaktu - waktu tanpa harus meminta nilai siswa berupa lembaran kertas yang telah dicetak. Cara kerja aplikasi yang dikembangkan dapat diilustrasikan seperti pada gambar 2 berikut ini.

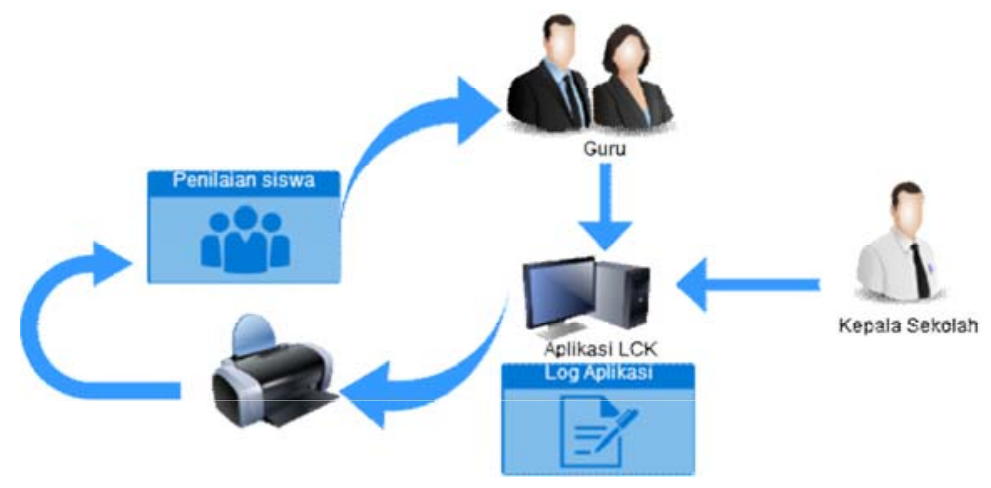

Gambar 4. Alur proses pada aplikasi

Gambar 4 menjelaskan tentang alur data pada aplikasi yang akan dikembangkan, dimana aplikasi tersebut berada pada server lokal di sekolah sehingga bisa diakses langsung oleh kepala sekolah, Guru dan wali kelas. Guru bisa langsung memberikan penilaian pada aplikasi yang akan di validasi oleh wali kelas. Sedangkan kepala sekolah akan menerima laporan dan memonitoring jalannya proses penilaian yang sewaktu - waktu dibutuhkan untuk 
pelaporan. Pada aplikasi ada catatan tentang penggunaan aplikasi yang bisa memonitoring jika terjadi perubahan data pada aplikasi.

\section{Hasil dan Pembahasan}

Pada aplikasi ini terdiri dari 4 modul inti yang terbagi dalam 2 modul untuk pengaturan data di awal sebelum aplikasi digunakan dan 2 modul yang akan sering digunakan selama proses penilaian berjalan. Pada 2 modul pengaturan data awal yaitu terdiri modul master data dan modul pengaturan aplikasi, sedangkan 2 modul lainnya adalah berkaitan dengan kesiswaan dan penilaian, seperti yang ditunjukkan pada gambar 5 berikut ini.

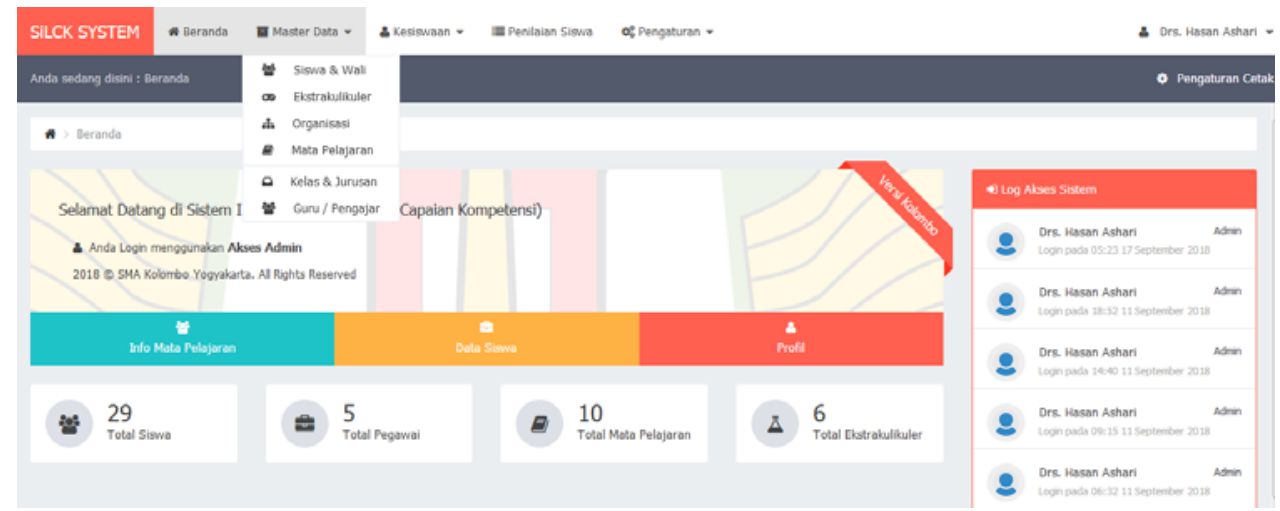

Gambar 5. Halaman utama aplikasi LCK

Pada halaman ini terdiri dari 4 menu utama yang masing - masing menu terdiri dari sub menu yang berfungsi sebagai pendukung. Pada menu master data terdiri dari menu data siswa dan wali, data ekstrakulikuler, data organisasi, data mata pelajaran, data kelas dan jurusan serta data guru / pengajar. Sedangkan untuk menu pengaturan terdiri dari profil sekolah, pengaturan nilai, pengaturan jenis kepribadian, pengaturan tahun ajaran, pengaturan kelas tahun ajaran, dan pengaturan tanggal rapor. Kedua menu ini termasuk dalam modul awal yang harus di isi terlebih dahulu dan diatur sebelum menggunakan aplikasi.

Untuk menu kesiswaan dan penilaian siswa masing - masing akan berfungsi jika data awal ( 2 modul awal) telah terisi dan di atur telebih dahulu. Menu kesiswaan terdiri dari sub menu kelas, penempatan siswa dan buku induk. Sedangkan menu penilaian berfungsi untuk melakukan penilaian terhadap siswa berdasarkan kelas dan tahun ajaran serta semester yang berjalan.

\subsection{Hasil Implementasi}

Hasil implementasi aplikasi monitoring laporan capaian kompetensi siswa tidak disajikan secara keseluruhuan. Sebagai sampel, hasil yang disajikan dalam penelitian ini adalah sebagai berikut:

\subsubsection{Penilaian Siswa}

Pada halaman penilaian siswa terdiri dari kolom NIS, nama siswa, nilai pengetahuan, nilai psikomotorik, nilai Afektif dan ketercapaian, seperti yang ditunjukkan pada gambar 6 . Halaman ini berfungsi untuk melakukan proses penilaian siswa berdasarkan nilai pengetahuan, nilai psikomotorik dan nilai afektif siswa. 


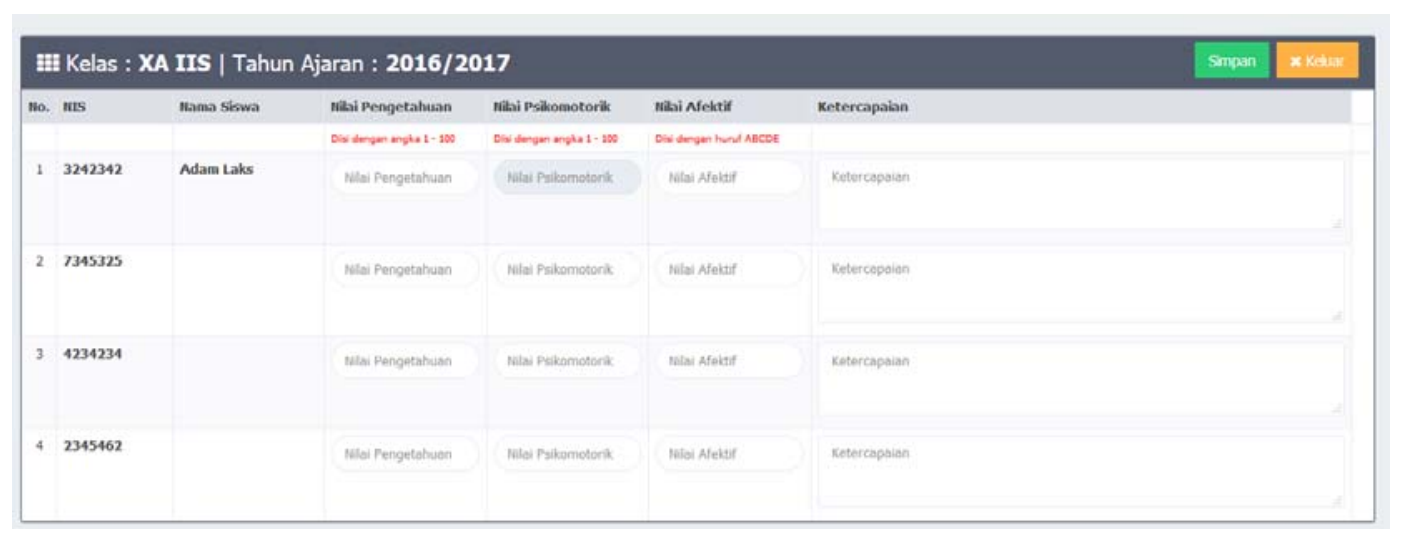

Gambar 6. Halaman penilaian siswa

Hasil dari proses penilaian siswa berupa sebuah laporan yang dapat dicetak dan di export dalam bentuk file excel sehingga mudah dalam penyimpanan dan percetakan, seperti pada gambar 7.

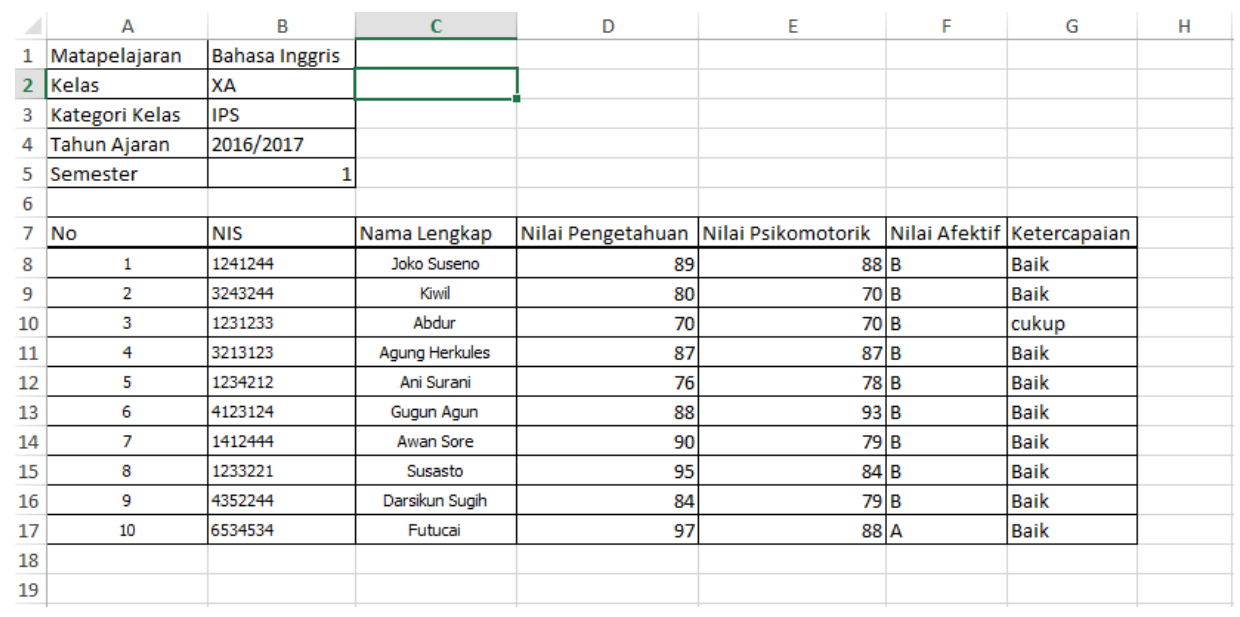

Gambar 7. Laporan hasil penilaian

Pada gambar 7 menunjukkan hasil export ke dalam file excel yang bisa disimpan dan diarsipkan untuk dijadikan data. Jika di perlukan maka akan dicetak sesuai dengan kebutuhan baik siswa ataupun wali siswa.

\subsubsection{Buku induk siswa}

Pada halaman buku induk siswa terdiri dari kolom NISN, NIS, nama siswa, kelulusan, peringkat dan aksi. Pada kolom kelulusan bisa diberikan 2 pilihan yaitu lulus atau tidak lulus, sedangkan pada aksi terdapat icon menu yang bisa digunakan untuk melihat detail siswa dan mengisi data setelah siswa tersebut lulus. Icon menu tersebut terdiri dari keterangan pendidikan siswa, keterangan setelah selesai siswa, keterangan perkembangan siswa, keterangan kesehatan siswa, keterangan kegemaran siswa, keterangan tempat tinggal siswa, cetak biodata buku induk dan export nilai buku induk seperti terlihat pada gambar 8 berikut ini. 


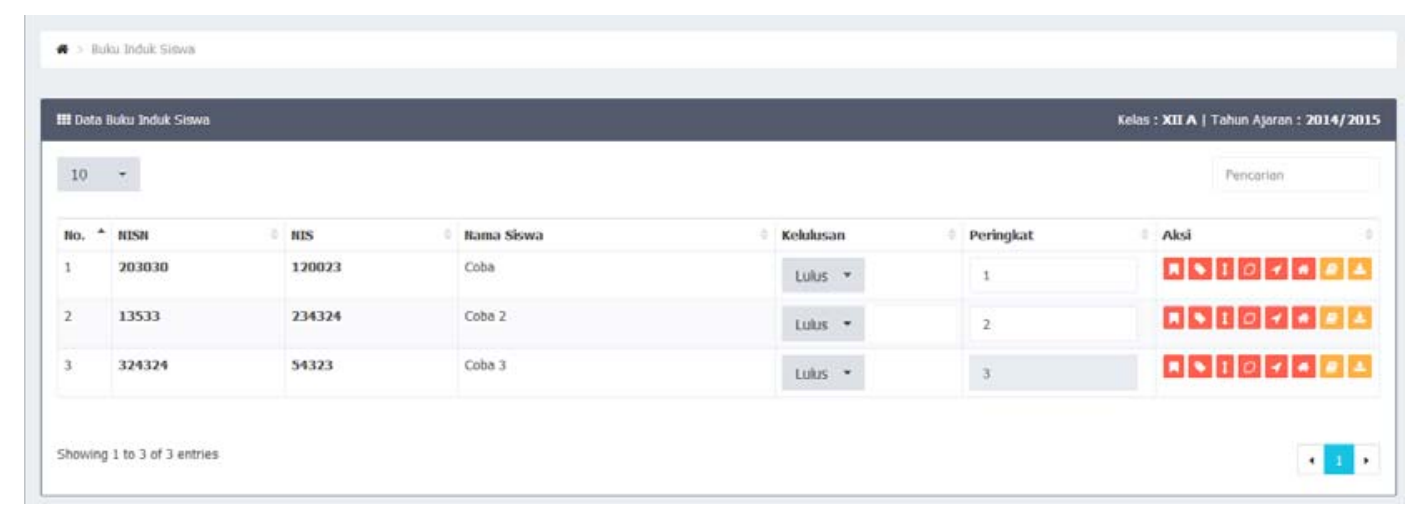

Gambar 8. Buku induk siswa

\subsection{Rencana pengujian}

Rencana pengujian pada Aplikasi monitoring capaian kompetensi peserta didik di SMA Kolombo yoyakarta, dengan menginput data kedalam aplikasi yang telah dibangun kemudian memperhatikan keluaran atau output dari hasil yang telah diinput. Rencana pengujian ini akan dikelompokan ke dalam suatu tabel. Dalam tabel tersebut berisi tentang item pengujian, deskripsi dan jenis pengujian.

\section{Kesimpulan}

Aplikasi yang dikembangkan telah memenuhi syarat untuk diterapkan di sma kolombo berdasarkan kebutuhan yang telah di analisa terlebih dahulu. Setelah melakukan analisis, perancangan aplikasi, pengujian dan implementasi, maka diperoleh kesimpulan dan saran sebagai catatan penting untuk pembangunan sistem perangkat lunak selanjutnya.

\subsection{Kesimpulan}

kesimpulan yang telah di peroleh dari aplikasi monitoring capaian kompetensi peserta didik di SMA Kolombo diantaranya :

1. Proses penilaian pada aplikasi membutuhkan waktu lebih cepat untuk mendapatkan informasi maupun mencetak data sehingga orang tau / wali siswa tidak perlu menunggu lama untuk mendapatkan informasi tersebut.

2. Para guru dan wali kelas dapat dengan mudah mendapatkan informasi tentang nilai siswa dan kemajuan siswa sehingga mudah untuk di monitoring.

3. Kepala sekolah dapat mengakses aplikasi untuk memonitoring baik siswa dan guru selama pelajaran dan semester berlangsung.

\subsection{Saran}

Dalam pembanguna aplikasi ini masih banyak kekurangan - kekurangan yang belum terpenuhi, maka dari itu perlu dilakukan pengembangan lebih lanjut. Adapun saran untuk pengguna aplikasi yang telah dibuat sebagai berikut :

1. Diharapkan pada pengembangan aplikasi berikutnya agar mengembangkan dalam versi mobile.

2. Diharapkan untuk pengembangan aplikasi ini lebih diperluas lagi untuk lingkup kerja aplikasi dengan membuat sistem informasi akademik sekolah 


\section{Daftar Pustaka}

[1] Handoko, T., 2012. Analisis Perancangan Sistem Informasi Nilai Siswa di SMP Negeri 1 Kersana Brebes. Naskah Publikasi. Yogyakarta: STMIK AMIKOM.

[2] Lukman, 2011. Sistem Informasi Pengolahan Nilai dan Data Siswa SMK Yapimda Jakarta. Faktor Exacta, 5(3), pp.217-27.

[3] Merindasari, E., Widyaningtyas, T. \& Arifin, M.Z., 2015. Sistem Informasi Penilaian Akademik Siswa Kurikulum 2013 Berbasis Web di SMAN 1 Trenggalek. In Seminar Nasional Sistem Informasi Indonesia. Surabaya, 2015.

[4] Nugroho, S.W. \& Utami, E., 2015. Pembangunan Sistem Monitoring dan Penilaian Siswa Berbasis Web (Studi Kasus: SMA Negeri 4 Surakarta). Naskah Publikasi. Yogyakarta: STMIK AMIKOM.

[5] Pressman, R.S. \& Maxim, B.R., 2001. Software Engineering A Practitioner's Approach. 8th ed. New York: McGraw-Hill Education.

[6] Trisnaningtyas, V., 2017. Aplikasi Laporan Pencapaian Kompetensi Peserta Didik Berdasarkan Kurikulum 2013 di SMP Negeri 1 Pacitan. Skripsi. Yogyakarta: Fakultas Ilmu Komputer Universitas AMIKOM. 